\title{
Participação do ácido úrico em doenças neurodegenerativas
}

\section{Uric acid role in neurodegenerative diseases}

Celmir de Oliveira Vilaça ${ }^{1}$, Márcia Cristina Antunes Ribas ${ }^{1}$, Marco Antônio Araujo Leite ${ }^{1}$, Raphael Breder ${ }^{1}$, Bruno Lima Pessoa ${ }^{2}$, Victor Hugo Bastos ${ }^{3}$, Carlos Eduardo Cardoso4, Rosano Fiorelli ${ }^{4}$, Stenio Fiorelli ${ }^{4}$, Giseli Roque de Souza ${ }^{4}$, Adalgiza Mafra Moreno ${ }^{5}$, Silmar Teixeira $^{3}$, Eduardo Jorge Custódio ${ }^{6}$, Marco Orsini ${ }^{4,5}$

1.Universidade Federal Fluminense. MMC/Divisão de Neurologia, HUAP. Programa de pós-graduação em Neurologia/Neurociências, UFF, Niterói-RJ, Brasil.

2.Universidade Federal Fluminense. Professor Assistente, Divisão de Neurocirurgia, HUAP, Niterói-RJ, Brasil.

3. Universidade Federal do Piaui- Laboratório de Mapeamento Cerebral e Funcionalidade - UFPI.

4. Universidade de Vassouras - Programa de Iniciação Cientifica e Mestrado em Ciências Aplicadas em Saúde. Brasil.

5. Universidade Iguaçu - UNIG - Rio de Janeiro. Brasi

6. Hospital Pedro Ernesto - UERJ - Departamento de Neurofisiologia. Brasi

\section{Resumo}

Objetivo. Revisão abordando a correlação entre os níveis de ácido úrico e doenças neurodegenerativas. Método. Revisão não sistemática utilizando a plataforma Google Acadêmico de artigos relacionando os níveis de ácido úrico em doenças neurodegenerativas de alta prevalência. Resultados. Foram utilizados 70 artigos em inglês para confecção desta revisão. Conclusão. O ácido úrico principalmente através de seu efeito antioxidante pode participar da fisiopatologia de diversas condições neurodegenerativas. Sendo um biomarcador de mensuração fácil e de baixo custo estudos sobre o ácido úrico poderão auxiliar no diagnóstico, prognóstico e terapias destas patologias neurodegenerativas.

Unitermos. Ácido Úrico; Biomarcadores; Estresse Oxidativo

\begin{abstract}
Objective. We realize a review about the role of uric acid in neurological diseases. Method. We perform a Non-systematic review using the Google Scholar platform of articles addressing uric acid levels in neurological diseases. Results. We used 70 articles in English language to make in this review. Conclusion. Uric acid through your antioxidant capacities may participate in the pathophysiology of several neurological disorders. As biomarker your Mensuration is simple and inexpensive. Studies involving uric acid may aid in the diagnosis, prognosis, and therapies in many neurological diseases.
\end{abstract}

Keywords. Uric Acid; Biomarkers; Oxidative Stress

Trabalho realizado na Universidade Federal Fluminense, Brasil.

Conflito de interesse: não Recebido em: 2018 Aceito em: 2018

Endereço para correspondência: Marco Orsini. Rua Tavares de Macedo, 95/902. Icaraí. Niterói-RJ. CEP: 24220-215. E-mail: orsinimarco@gmail.com 


\section{INTRODUÇÃO}

Durante a evolução das espécies a vida terrestre só foi conseguida através de menor consumo de água para eliminação de produtos do metabolismo ${ }^{1}$. Compostos nitrogenados tóxicos são derivados do metabolismo de proteínas, ácidos nucleicos e purinas. Animais aquáticos inferiores liberam amônia como principal produto nitrogenado. Répteis e aves evoluíram para a eliminação de ácido úrico $(\mathrm{AU})$ ao invés de amônia ${ }^{1,2}$. O homem como outros mamíferos excreta preferencialmente ureia como principal subproduto do metabolismo do nitrogênio. Distúrbios do ciclo da ureia nos seres humanos causam aumento da produção de amônia com encefalopatia ${ }^{3}$. Além da ureia, o homem também possui a capacidade de excreção de $A U$. Este deriva do metabolismo das purinas, originando além do ácido úrico alantoína e ácido alantóico em menores quantidades (Figura 1$)^{1,2,4,5}$. Os hominídeos perderam a capacidade de degradação de ácido úrico sendo este eliminado quase exclusivamente através dos rins ${ }^{4,5}$. 0 AU é o principal antioxidante plasmático sendo responsável por $60 \%$ da capacidade antioxidante sérica ${ }^{6-8}$.

Por outro lado, tanto no envelhecimento como em centenas de doenças, dentre elas os mais variados tipos de câncer, suspeita-se da participação do estresse oxidativo. Estresse oxidativo é um termo criado em 1985 por Helmut Sies e representa a diferença no balanço de substâncias pró e antioxidante em favor das primeiras ${ }^{4}$. Há a formação de radicais livres derivados do oxigênio e nitrogênio. Estes 
radicais se originariam tanto de reações inflamatórias em locais de lesão tecidual como também de disfunção mitocondrial. O sistema nervoso central (SNC) devido ao seu alto consumo de oxigênio é um ambiente altamente favorável a formação de espécies reativas de oxigênio (ERO) e nitrogênio (ERN) ${ }^{9}$. Estas acarretam danos em diversos constituintes intracelulares. Ocorre nitrosilação do aminoácido tirosina em proteínas e alterações dos ácido nucleico das células, seja DNA ou RNA. Lesões no DNA podem causar ativação de proteínas iniciadoras de apoptose ou morte celular ${ }^{10,11}$. Radicais livres também provocam peroxidação lipídica. O alto conteúdo de gordura insaturada na mielina também colabora para tornar o SNC mais susceptível a lesão por radicais livres ${ }^{7}$.

Entre os sistemas depuradores de radicais livre além do AU podemos citar os sistemas enzimáticos como a catalase, superóxido dismutase, glutationa peroxidase e as substâncias não enzimáticas como tocoferol, coenzima $Q_{10}$, ácido ascórbico (vitamina C) e a albumina ${ }^{12,13}$.

Podemos definir biomarcador como uma característica objetivamente medida e avaliada como um indicador de um processo biológico normal, processo patológico ou resposta a uma intervenção terapêutica ${ }^{14}$. Neste contexto, o papel do $\mathrm{AU}$ como antioxidante e sua medida fácil e de baixo custo tornam o seu uso como biomarcador uma promissora área de pesquisa. 


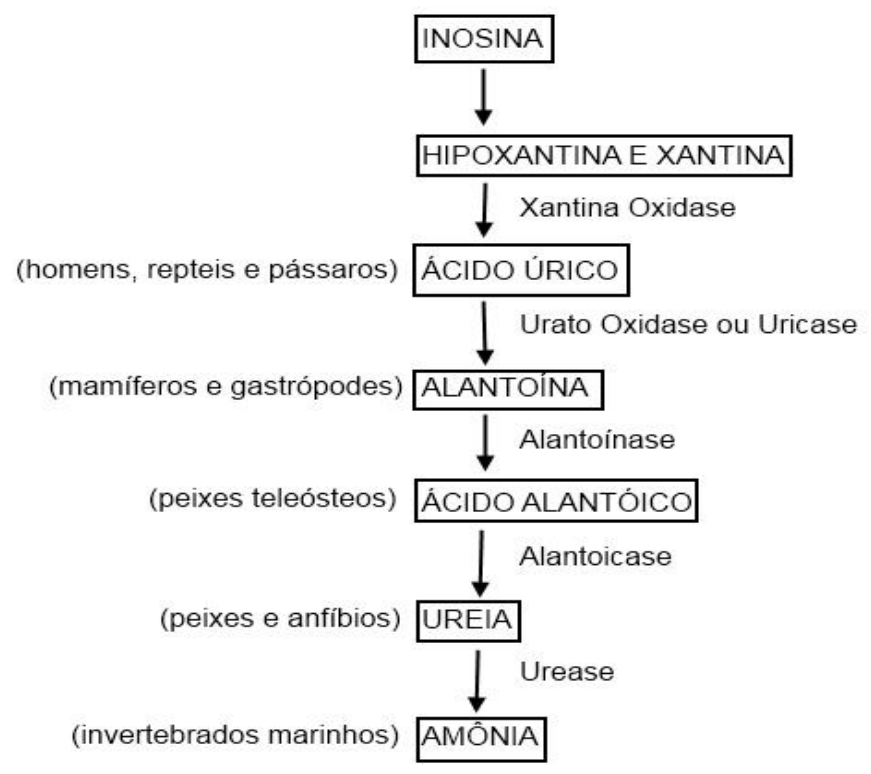

Figura 1. Metabolismo das purinas durante a evolução das espécies.

\section{MÉTODO}

Realizamos uma revisão não sistemática de artigos no Google Acadêmico entre o período de Janeiro de 2003 até Março de 2019. Priorizou-se artigos em inglês apresentando os descritores: "uric acid" ou "urate" conjuntamente com doenças neurodegenerativas de elevada prevalência: "Parkinson's Disease", Alzheimer, "multiple sclerosis" e "stroke" e obtivemos 338 artigos. Não houve critérios específicos para seleção de artigos. Alguns periódicos foram escolhidos a partir das referências da busca inicial enquanto outros por abordar a participação do ácido úrico em doenças neurodegenerativas de menor prevalência. Incluímos artigos experimentais, de revisão, relatos de casos e opiniões de especialistas. Utilizamos ao todo 70 artigos em inglês nesta revisão. 


\section{RESULTADOS E DISCUSSÃO \\ O Ácido Úrico}

O ácido úrico é um composto heterocíclico de carbono, oxigênio e nitrogênio de fórmula $\mathrm{C}_{5} \mathrm{H}_{4} \mathrm{~N}_{4} \mathrm{O}_{3}{ }^{15}$. Seu nome químico é (7,9- dihidro-1H-purina-2,6,8(3H)-triona), sendo uma molécula de 160 daltons ${ }^{16}$. É também um ácido orgânico fraco que existe sob a forma não ionizada em $\mathrm{pH}<5,75$ e forma de íon urato em maiores valores $\mathrm{pH}^{17}$. Há mais de 20 milhões de anos o homem perdeu a capacidade de degradar o ácido úrico em alantoína pela perda do gene da enzima uricase ou urato oxidase. Sugere-se a ocorrência de altas pressões seletivas do meio ambiente acarretando esta mutação em hominídeos, pois a homozigose da mutação do gene da uricase é fatal em primatas inferiores. Tal fenômeno explicaria o homem apresentar concentração de ácido úrico 10 vezes maior em comparação a outros mamíferos menos evoluídos ${ }^{18}$.

Existem três hipóteses para os altos níveis de ácido úrico no Homo sapiens. Na primeira o ácido úrico pode ter sido importante para manutenção da pressão arterial e de perfusão cerebral na evolução para postura bípede em períodos remotos de baixo consumo dietético de $\mathrm{sal}^{9,18}$. Níveis séricos normais de $A U$ estão entre de 2 a $3 \mathrm{mg} / \mathrm{dl}$ nos mamíferos inferiores e 3 a $4 \mathrm{mg} / \mathrm{dl}$ nos homens préhistórico enquanto no homem atual variam entre $7 \mathrm{mg} / \mathrm{dl}$ no homem e $6 \mathrm{mg} / \mathrm{dl}$ na mulher ${ }^{16}$. Outra possibilidade justificando seus elevados valores no homem moderno é sua ação antioxidante. A descoberta das propriedades 
antioxidantes do AU foi feita por Ames em 1982 ao observar a sua atuação em casos de câncer ${ }^{6}$. O AU pode ter assumido este papel em substituição a nossa perda de capacidade de síntese de vitamina $\mathrm{C}$ em épocas anteriores a perda da uricase. Ademais, in vivo o AU tem a capacidade de estabilizar outros antioxidantes naturais como a vitamina $\mathrm{C}$ e a superóxido dismutase (SOD). Por último altos níveis de $\mathrm{AU}$ podem estar relacionados ao desenvolvimento cognitivo do homem. O AU apresenta potencial efeito neuroestimulante e supõe-se ser esta capacidade derivada de sua estrutura química similar a cafeína ${ }^{9,19}$.

A concentração de $A U$ no líquor é $7 \%$ da concentração plasmática $^{20}$. A concentração sérica é muito próxima ao limite de solubilidade do AU no soro ${ }^{16}$. A maior parte do ácido úrico endógeno advém do metabolismo intracelular das purinas. Estas derivam dos ácidos nucleicos celulares (RNA e DNA) e do metabolismo do ATP ${ }^{21}$.

As principais patologias associadas a presença de hiperuricemia são a gota e nefrolitíase. A gota é a principal causa de artrite inflamatória aguda em homens acima de 40 anos e se apresenta inicialmente como podagra. A podagra pode ser definida como a dor aguda com eritema e edema das articulações metatarsofalangeanas ${ }^{22}$. Por outro lado a nefrolitíase por ácido úrico é segunda causa de cálculo na população geral. Está abaixo somente dos casos de nefrolitíase por oxalato de cálcio. Representa $20 \%$ dos 
cálculos na população geral e $50 \%$ dos cálculos em pacientes com gota ${ }^{23,24}$.

\section{O Ácido Úrico e Doenças Neurodegenerativas}

\section{Doenças neurodegenerativas por alterações diretas do metabolismo purinérgico}

Entre as doenças neurodegenerativas causadas diretamente por mutações em enzimas do metabolismo do ácido úrico destaca-se a Síndrome de Lesch-Nyhan (SLN). A SLN foi a primeira desordem psiquiátrica atribuída a um defeito enzimático ${ }^{1}$. Caracteriza-se por ser uma síndrome genética ligado ao cromossomo $X$, sendo causada por mutações da HGPRT (Hipoxantina-Guanina-PolirobosilTransferase). Há presença de gota e insuficiência renal por hiperuricemia pronunciada associada a transtornos do movimento e automutilação ${ }^{16}$.

\section{2.Ácido úrico e Doença de Parkinson}

A doença de Parkinson (DP) é a segunda doença degenerativa mais frequente do SNC, superada pela doença de Alzheimer ${ }^{25}$. Clinicamente é caracterizada pela presença de sua tétrade de achados motores: tremor de repouso, bradicinesia, rigidez e instabilidade postura ${ }^{26}$. $\mathrm{Em}$ termos patológicos há a degeneração dos neurônios dopaminérgicos da substância negra do mesencéfalo. Esta degeneração poderia ser desencadeada por disfunção mitocondrial com produção de radicais livres. A DP se 
caracteriza pelo acúmulo de agregados de a-sinucleína formando os corpos de Lewy. Os corpos de Lewy podem adquirir sua forma insolúvel devido a presença de estresse oxidativo. Tal fato pode ser evidenciado pela presença de nitrosilação de resíduos de tirosina nos corpos de Lewy $^{27,28}$. Em modelos animais o ácido úrico previne lesão e morte celular nos neurônios dopaminérgicos. A proteção também pode advir da capacidade do ácido úrico de atuar como quelante de ferro. O ferro iônico atua na produção de radicais livres na substância negra mesencefálica. A substância negra é uma região do SNC com grande potencial de produção de radicais livres devido a intensa oxidação enzimática e não enzimática durante o metabolismo da dopamina ${ }^{29,30}$. Pacientes com DP apresentam menores níveis de ácido úrico na substância negra em relação aos controles, assim como no soro e no líquor $^{17}$. Indivíduos com DP e baixos níveis de AU também apresentam menores níveis de captação de dopamina no estriado observado através de exames de medicina nuclear ${ }^{31-33}$. Supõe-se ser a forma tremulante da DP de melhor prognóstico quando comparada as formas rígidoacinéticas. Maiores níveis de $A U$ são observados em pacientes com a forma tremulante da DP em comparação as formas rígido-acinéticas ${ }^{34}$. Ressalte-se que a terapia com levodopa sabidamente aumenta a reabsorção renal de acido úrico. Apesar disso os níveis de AU podem decair com a progressão dos estágios da DP de forma independente do aumento da dose total diária de levodopa $33,35,36$. Por outro 
lado a alantoína pode servir de marcador de estresse oxidativo por derivar de oxidação não enzimática do AU. Estudo da relação entre alantoína e $A U$ na urina de pacientes com DP sugerem ser os baixos níveis de AU um processo crônico de baixa produção e não originado a partir do seu consumo pela progressão da DP ${ }^{21}$.

Quando uma condição é considerada fator de risco para uma doença, mutações que alteram este fator de risco devem também modificar o risco para a doença. Assim sendo mutações em transportadores de ácido úrico e outros genes reguladores de seus níveis plasmáticos já foram associados a maior risco de $\mathrm{DP}^{32,37}$.

A cafeína por apresentar estrutura similar ao ácido úrico possivelmente também atua como antioxidante. Esta característica pode explicar a relação inversa entre consumo de café e ocorrência de Doença de Parkinson e esclerose múltipla ${ }^{36}$. Baixos níveis de ácido úrico também estão associados a pior desempenho cognitivo em pacientes com DP e maiores índices de apatia independentemente da existência de depressão ou demência ${ }^{38-41}$.

Encontramos também relação entre a presença de sintomas não motores na DP, como sono, fadiga $e$ transtorno do humor em pacientes com DP e baixos níveis de $\mathrm{AU}^{42}$. Estes achados indicam ter $\mathrm{O} U \mathrm{U}$ efeito neuroprotetor em neurônios serotoninérgicos além dos dopaminérgicos ${ }^{43}$. Pacientes com transtorno comportamental do sono REM e baixos níveis séricos de ácido úrico progridem para DP de forma mais rápida 
quando comparados a indivíduos com níveis séricos elevados ${ }^{44}$. Assim sendo, existe a possibilidade de aumento dos níveis de AU diminuir a progressão da DP. A inosina é um precursor do ácido úrico utilizado por atletas de alta performance. A inosina provoca aumento dos níveis séricos de ácido úrico e apresenta a vantagem de não ser metabolizada pela flora intestinal ${ }^{17,45}$. A administração de inosina poderia lentificar a progressão da DP. Ademais a participação de dano oxidativo na formação de Corpos de Lewy sugere que outros tipos de pakinsonismo podem se caracterizar por níveis de $\mathrm{AU}$ reduzidos como a $\mathrm{AMS}^{27}$. Interessantemente, A paralisia supranuclear progressiva (PSP) também apresenta diminuição dos níveis séricos de AU em comparação a controles. Contudo como níveis de AU estariam relacionados a PSP é desconhecido pois a PSP é considerada uma tauopatia e não uma a-sinucleinopatia ${ }^{46}$.

\section{3.Ácido úrico e doenças desmielinizantes}

A esclerose múltipla (EM) é a principal doença neurológica não traumática incapacitante em jovens economicamente ativos ${ }^{47}$. Acomete preferencialmente mulheres e caracteriza-se por surtos recorrentes de desmielinização do SNC, podendo ser acompanhada de lesão neuronal associada. Apresenta entre principais subtipos clínicos a forma surto-remissão, mais frequente, acompanhada pelas formas secundariamente progressiva, primariamente progressiva e forma benigna ${ }^{48}$. 
Espécies reativas de oxigênio, em especial os peroxinitritos tem sido relacionados a lesões de esclerose múltipla e a encefalite alérgica experimental ${ }^{20}$. Estes derivam do oxido nítrico presente nos macrófagos e astrócitos da placas desmielinizantes ${ }^{5,45,49}$. O ácido úrico funcionaria como um removedor de peroxinitritos. Indivíduos com esclerose múltipla apresentam menores níveis de ácido úrico quando comparados a controles. Além disso estudos epidemiológicos indicam a quase inexistência de casos de esclerose múltipla em indivíduos com gota $^{5,50,51}$. Os níveis de ácido úrico também ajudam a explicar a maior incidência de EM no sexo feminino, pois estas possuem menores níveis de $A U$ em relação aos homens ${ }^{8}$. Sabe-se ocorrer aumento dos níveis de uratos em pacientes tratados para EM. Este aumento ocorre tanto no tratamento dos surtos com pulsoterapia utilizando corticoides como após tratamento preventivo de novos surtos com acetato de glatirâmer ou $\beta$-interferon. Este achado indica a possibilidade do papel do ácido úrico como um possível marcador de resposta ao tratamento $50,52,53$. Modelos animais de encefalite alérgica experimental associam o aumento dos níveis de AU a menor progressão da doença ${ }^{8,33}$. Níveis de $A U$ também são encontrados reduzidos na urina de pacientes com EM, indicando maior consumo de AU para manutenção do balanço oxidativo, especialmente pela remoção dos peroxinitritos. Contudo, assim como na DP, deve-se ressaltar a dificuldade de determinar se os baixos níveis do ácido úrico são causa ou 
consequência tanto na EM como em outras doenças neurodegenerativas ${ }^{51}$. Em contrapartida, pacientes com Síndrome Clínica Isolada (CIS) apresentam níveis de uratos diminuídos, indicando serem os níveis reduzidos de $A U$ causa e não consequência da $\mathrm{EM}^{45}$. Indivíduos em surtos clínicos ou com lesões ativas de EM na ressonância magnética de crânio apresentam níveis menores de $A U$ quando comparado aos períodos de remissão da doença. Menores níveis de $A U$ durante os surtos também se associam a pior desempenho na escala EDSS ${ }^{51,53}$. A administração de inosina acarreta melhora clínica e diminuição dos índices de surtos em pacientes com EM ${ }^{45}$.

Os níveis de $A U$ são 10 vezes menores no líquor em comparação aos do soro ${ }^{9,29}$. O quociente entre os níveis de AU no soro/liquor pode auxiliar na estimativa de quebra da barreira hematoencefálica durante um surto de EM assim como os níveis de albumina ${ }^{50}$. O aumento dos níveis de $A U$ no líquor possivelmente se deve também ao aumento do catabolismo das purinas como ATP durante ao estado inflamatório do SNC característico da EM ${ }^{12}$.

Considerando-se outras doenças desmielinizantes há estudos entre os níveis de $A U$ e a neurite óptica e neuromielite óptica. A primeira pode ser considerada uma forma frustra ou inicial de EM. Há evidências de níveis reduzidos de $A U$ na neurite óptica independentemente de sua conversão para EM. Este achado também é utilizado para associar os níveis de uratos a causa e não consequência da $\mathrm{EM}^{54}$. 
Menores níveis de AU são observados em pacientes com neuromielite óptica em comparação a controles. Ademais os níveis de AU nos surtos são menores em comparação aos períodos estáveis da doença. Apesar da lesão preferencialmente astrocitária pelos anticorpos antiaquaporina 4 também ocorreria lesão por estresse oxidativo da oligodendroglia rica em lipídios na mielina. Nesse contexto os níveis de AU poderiam servir de biomarcador para avaliação de resposta tratamento ${ }^{55}$.

\section{4.Ácido úrico e Doença de Alzheimer}

Níveis elevados de ácido úrico estão associados a menores riscos de demência quando excluídos outros fatores de risco relacionados a dano vascular como hipertensão, dislipidemia e diabetes ${ }^{56}$. O ácido úrico através do estímulo a síntese de receptores EAAT (transportadores de aminoácidos excitatórios) nos astrócitos diminuiria a excitotoxicidade induzida pelo glutamato nos neurônios circundantes $^{16}$. O AU também atenuaria a lesão oxidativa e mitocondrial pela formação de $\beta$-amiloide ${ }^{57}$. Em associação, a angiopatia amiloide é uma doença também caracterizada pela alta produção de $\beta$-amiloide. Baixos níveis de uratos estão associado ao aumento do risco de sangramento em casos de angiopatia amiloide ${ }^{58}$. 0 ácido úrico também pode diminuir o estresse oxidativo causado pela proteína tau independente de sua ação atuação no $\beta$-amiloide ${ }^{57}$. Ressaltamos entretanto a existência de trabalhos não evidenciando o aumento de risco de DA em pacientes com 
redução dos níveis de $A U$. Possivelmente isto se deve a falta de correção para outros fatores de risco associados a elevados níveis de uratos como a hipertensão arterial e a síndrome metabólica, sabidamente fatores de risco para $\mathrm{DA}^{59}$.

\section{5.Ácido úrico e doença cerebrovascular}

O endotélio vascular estimulado por AU produz fatores quimioatrativos de macrófagos para infiltração em vasos ateroscleróticos ${ }^{20,60}$. O AU aumenta a peroxidação lipídica e do LDL com aumento da adesividade plaquetária e formação de trombos ${ }^{59}$. O AU também acarretaria elevação da pressão arterial pela diminuição da síntese de óxido nítrico (ON) pelas células endoteliais, com aumento da resistência vascular ${ }^{61}$. Outra teoria indica que a hiperuricemia pode causar lesão endotelial através da produção de radicais livres pelo aumento da atividade da enzima xantina oxidase (XO). A XO origina AU a partir do metabolismo de xantinas e hipoxantinas. Isto explicaria o efeito benéfico do uso de inibidores da xantina oxidase como o alopurinol na diminuição do risco cerebrovascular em pacientes com gota ${ }^{62}$. Ademais a hiperuricemia também está associada a aterosclerose carotídea independente da presença de outros fatores de risco vascular ${ }^{22}$. Altos níveis de $A U$ estão associados a maior produção de agentes pró inflamatórios como proteína $C$ reativa (PCR) e interleucina 6 (IL-6). Sabidamente a PCR é fator independente para o aumento do risco de infarto do miocárdio ${ }^{28}$. A hiperuricemia 
também é responsável por aumento da mortalidade por todas as causas vasculares na doença renal crônica. Esta decorre da formação de cálculos de ácido úrico e da nefrite intersticial decorrente da reação inflamatória a estes cálculos no interstício do parênquima renal ${ }^{22,63}$. O AU também pode acarretar dano vascular renal por alterações do sistema renina angiotensina aldosterona ${ }^{64}$. Há de se ressaltar novamente a dificuldade de associação inequívoca entre hiperuricemia e dano vascular pela frequente comorbidade de elevados níveis de uratos com outros fatores de risco vascular como hipertensão arterial sistêmica (HAS) ${ }^{18,19}$. Há estudos, entretanto, evidenciando a ligação entre níveis aumentados de $\mathrm{AU}$ e dano vascular renal e cardíaco quando corrigidos para outros fatores de risco $^{64}$. Em contrapartida, jovens com HAS e hiperuricemia apresentam melhora dos seus níveis tensionais se tratados precocemente para a hiperuricemia ${ }^{62}$.

Em contrapartida, apesar de muitos trabalhos associando a relação entre hiperuricemia e dano vascular, o AU através de seu efeito antioxidante pode apresentar papel benéfico em situações de doença cerebrovascular. Pacientes na fase aguda do AVC com altos níveis séricos de AU apresentam infartos de menores tamanhos, com baixa incidência de infartos malignos de cerebral média e de transformação hemorrágica. Cria-se assim a possibilidade de infusão de AU conjuntamente com r-TPA para melhor tratamento trombolítico do AVC na fase aguda ${ }^{65,66}$. 


\section{6.Ácido úrico e outras doenças neurodegenerativas}

O ácido úrico também é associado a outras doenças neurodegenerativas entretanto com menor número de trabalhos publicados. Pode haver correlação entre níveis de AU e o trauma espinhal agudo, Esclerose Lateral Amiotrófica e a Doença de Hungtinton ${ }^{67}$.

Em se tratando de trauma espinhal agudo há melhora do quadro com infusão de $A U$ atribuindo-se isto a diminuição da excitotoxidade glutamatérgica e diminuição de dano oxidativo. O dano oxidativo como já abordado provoca a geração de peroxinitritos. Além da lesão a macromoléculas diretamente, a lesão do DNA por peroxinitritos ativaria a enzima PARP (poly-ADP ribose polimerase) causando morte celular por apoptose ${ }^{10}$.

O controle da excitotoxidade do glutamato também seria o mesmo modo de atuação dos níveis de ácido úrico na esclerose lateral amiotrófica, com baixos níveis séricos associado ao aumento do risco da doença ${ }^{67}$. Por último, embora níveis reduzidos de uratos estejam associados a maior taxa de progressão da Doença de Hungtinton, onde também se especula a participação do estresse oxidativo, há raros estudos com a doença ${ }^{68}$.

Por último aventa-se a possibilidade similaridades fisiopatológicas e epidemiológicas entre a Doença de Parkinson e o tremor essencial, com a possibilidade de participação de estresse oxidativo em ambas enfermidades. Os poucos estudos a avaliar os níveis de ácido úrico no tremor essencial não evidenciaram alterações de seus 
níveis quando em comparação com controles, diferentemente do que ocorre na DP. Entretanto maiores níveis de $\mathrm{AU}$ estariam associados a menor gravidade do tremor 69,70 .

\section{CONCLUSÃO}

O ácido úrico através principalmente de seus efeitos antioxidantes pode participar da fisiopatologia de diversas enfermidades neurodegenerativas, sendo as mais estudadas a Doença de Parkinson, Esclerose Múltipla, Doença de Alzheimer e doença cerebrovascular. Não se sabe em muitas delas se a alteração dos níveis de AU é primária ou secundária ao processo patológico. Existe a possibilidade terapêutica no uso de uratos tanto pela sua administração direta em doenças como AVC ou através de seus precursores como a inosina em outras condições neurodegenerativas. A mensuração do ácido úrico é fácil e de baixo custo. Isto torna o estudo do ácido úrico como biomarcador um interessante campo de pesquisa para diagnóstico, prognóstico e tratamento em muitas afecções neurológicas.

\section{REREFÊNCIAS}

1.Skinner KA, Parks DA, Khoo NH. Uric Acid Metabolism. Encyclopedia of Life Sciences. Chichester: John Wiley \& Sons Ltd; 2006. p1-9.

2.Alvarez-Lario B, Macarrón-Vicente J. Evolution of Uric Acid Metabolism in Humans. Encyclopedia of Life Sciences. Chichester: John Wiley \& Sons Ltd; 2013. p1-9.

3.Atya HB, Ali SA, Hegazy MI, El Sharkawi FZ. Urinary Urea, Uric Acid and Hippuric Acid as Potential Biomarkers in Multiple Sclerosis Patients. Indian J Clin Biochem 2017;33:163-70. http://dx.doi.org/10.1007/s12291-017-0661-6

4.Glantzounis G, Tsimoyiannis E, Kappas A, Galaris D. Uric Acid and 
Oxidative Stress. Curr Pharm Des 2005;11:4145-51. http://dx.doi.org/10.2174/138161205774913255

5.Koch $M$, Keyser J. Uric acid in multiple sclerosis. Neurol Res 2006;28:316-9. https://doi.org/10.1179/016164106X98215

6.Aydin O, Kurtulus $F$, Eren E, Ellidag HY, Yılmaz N, Yaman A. Balanced oxidative stress index in spite of decreased uric acid levels in multiple sclerosis patients. Neurochem J 2015;9:153-8. https://doi.org/10.1134/S1819712415020026

7.Al-Khateeb E, Althaher A, Al-Khateeb M, Al-Musawi H, Azzouqah O, Al-Shweiki $S$, et al. Relation between uric acid and Alzheimer's disease in elderly Jordanians. J Alzheimer's Dis 2015;44:859-65. https://doi.org/10.3233/JAD-142037

8.Dujmovic I, Pekmezovic T, Obrenovic R, Nikolić A, Spasic M, Mostarica Stojkovic $M$, et al. Cerebrospinal fluid and serum uric acid levels in patients with multiple sclerosis. Clin Chem Lab Med 2009;47:848-53. https://doi.org/10.1515/CCLM.2009.192

9.Cipriani S, Chen X, Schwarzschild MA. Urate: a novel biomarker of Parkinson's disease risk, diagnosis and prognosis. Biomark Med 2010;4:701-12. https://doi.org/10.2217/bmm.10.94

10.Scott GS, Cuzzocrea S, Genovese T, Koprowski H, Hooper DC. Uric acid protects against secondary damage after spinal cord injury. Proc Natl Acad Sci USA 2005;102:3483-8.

https://doi.org/10.1073/pnas.0500307102

11.Anderson RF, Harris TA. Dopamine and Uric Acid Act as Antioxidants in the Repair of DNA Radicals: Implications in Parkinson's Disease. Free Radic Res 2003;37:1131-6. https://doi.org/10.1080/10715760310001604134

12.Amorini AM, Petzold A, Tavazzi B, Eikelenboom J, Keir G, Belli A, et al. Increase of uric acid and purine compounds in biological fluids of multiple sclerosis patients. Clin Biochem 2009;42:1001-6. https://doi.org/10.1016/j.clinbiochem.2009.03.020

13.Peng $F$, Yang $Y$, Liu J, Jiang $Y$, Zhu $C$, Deng $X$, et al. Low antioxidant status of serum uric acid, bilirubin and albumin in patients with neuromyelitis optica. Eur J Neurol 2012;19:277-83. https://doi.org/10.1111/j.1468-1331.2011.03488.x

14.Atkinson AJ, Colburn WA, DeGruttola VG, DeMets DL, Downing GJ, Hoth DF, et al. Biomarkers and surrogate endpoints: Preferred definitions and conceptual framework. Clin Pharmacol Ther 2001;69:89-95. https://doi.org/10.1067/mcp.2001.113989

15.Pan M, Gao H, Long L, Xu Y, Liu M, Zou J, et al. Serum uric acid in patients with Parkinson's disease and vascular parkinsonism: a crosssectional study. Neuroimmunomodulation 2013;20:19-28. https://doi.org/10.1159/000342483

16.Fang $\mathrm{P}$, Li X, Luo JJ, Wang H, Yang XF. A Double-edged Sword: Uric Acid and Neurological Disorders. Brain Disord Ther 2013;2:21120. https://doi.org/10.4172/2168-975X.1000109

17.Schlesinger I, Schlesinger N. Uric acid in Parkinson's disease. Mov Disord 2008;23:1653-7. https://doi.org/10.1002/mds.22139

18.Spitsin S, Markowitz CE, Zimmerman V, Koprowski H, Hooper DC. 
Modulation of serum uric acid levels by inosine in patients with multiple sclerosis does not affect blood pressure. J Hum Hypertens 2010;24:359-62. https://doi.org/10.1038/jhh.2009.83

19.Edwards NL. The role of hyperuricemia in vascular disorders. Curr Opin Rheumatol

2009;21:132-7.

https://doi.org/10.1097/BOR.0b013e3283257b96

20.Peng F, Zhang B, Zhong X, Li J, Xu G, Hu X, et al. Serum uric acid levels of patients with multiple sclerosis and other neurological diseases. Mult Scler J 2008;14:188-96. https://doi.org/10.1177/1352458507082143

21.Sampat R, Young S, Rosen A, Bernhard D, Millington D, Factor S, et al. Potential mechanisms for low uric acid in Parkinson disease. J Neural Transm (Vienna) 2016;123:365-70. https://doi.org/10.1007/s00702-015-1503-4

22.Baker JF, Ralph Schumacher H. Update on gout and hyperuricemia. Int J Clin Pract 2010;64:371-7. https://doi.org/10.1111/j.1742-1241.2009.02188.x

23. Hughes P. The CARI guidelines. Kidney stones epidemiology. Nephrology (Carlton) 2007;12:S26-30. https://doi.org/10.1111/j.1440-1797.2006.00724.x

24.Ferraro PM, Curhan GC. Serum Uric Acid and Risk of Kidney Stones. Am J Kidney Dis 2017;70:158-9. https://doi.org/10.1053/j.ajkd.2017.05.004

25.Tambosco L, Percebois-Macadrré L, Rapin A, Nicomette-Bardel J, Boyer FC. Effort training in Parkinson's disease: A systematic review. Ann Phys Rehabil Med 2014;57:79-104. https://doi.org/10.1016/j.rehab.2014.01.003

26.Poewe W, Wenning G. The differential diagnosis of Parkinson's disease. Eur J Neurol 2002;9:23-30. https://doi.org/10.1046/j.14681331.9.53.3.x

27.Lee JE, Song SK, Sohn YH, Lee PH. Uric acid as a potential disease modifier in patients with multiple system atrophy. Mov Disord 2011;26:1533-6. https://doi.org/10.1002/mds.23556

28.Kutzing MK, Firestein BL. Altered Uric Acid Levels and Disease States. Pharmacol Exp Ther 2008;324:1-7. https://doi.org/10.1124/jpet.107.129031

29.Chen X, Wu G, Schwarzschild MA. Urate in Parkinson's Disease: More Than a Biomarker? Curr Neurol Neurosci Rep 2012;12:367-75. https://doi.org/10.1007/s11910-012-0282-7

30.Kim T-H, Lee J-H. Serum Uric Acid and Nigral Iron Deposition in Parkinson's Disease: A Pilot Study. PLoS One 2014;9:1-4. https://doi.org/10.1371/journal.pone.0112512

31.Moccia M, Pappatà S, Erro R, Picillo M, Vitale C, Amboni M, et al. Uric acid relates to dopamine transporter availability in Parkinson's disease. Acta Neurol Scand 2015;131:127-31. https://doi.org/10.1111/ane.12295.

32.Facheris MF, Hicks AA, Minelli C, Hagenah JM, Kostic V, Campbell $S$, et al. Variation in the uric acid transporter gene SLC2A9 and its association with AAO of Parkinson's disease. J Mol Neurosci 
2011;43:246-50. https://doi.org/10.1007/s12031-010-9409-y

33.Andreadou E, Nikolaou C, Gournaras F, Rentzos M, Boufidou F, Tsoutsou $A$, et al. Serum uric acid levels in patients with Parkinson's disease: Their relationship to treatment and disease duration. Clin Neurol Neurosurg 2009;111:724-8.

https://doi.org/10.1016/j.clineuro.2009.06.012

34. Huertas I, Jesús S, Lojo JA, García-Gómez FJ, Cáceres-Redondo MT, Oropesa-Ruiz JM, et al. Lower levels of uric acid and striatal dopamine in non-tremor dominant Parkinson's disease subtype. PLoS One 2017; 12:e0174644.

https://doi.org/10.1371/journal.pone.0174644

35.Vieru E, Köksal A, Mutluay B, Dirican AC, Altunkaynak Y, Baybas $\mathrm{S}$. The relation of serum uric acid levels with I-Dopa treatment and progression in patients with Parkinson's disease. Neurol Sci 2016;37:743-7. https://doi.org/10.1007/s10072-015-2471-z

36.Annanmaki T, Muuronen A, Murros K. Low plasma uric acid level in Parkinson's disease. Mov Disord 2007;22:1133-7. https://doi.org/10.1002/mds.21502

37.González-Aramburu I, Sánchez-Juan P, Jesús S, Gorostidi A, Fernández-Juan E, Carrillo $F$, et al. Genetic variability related to serum uric acid concentration and risk of Parkinson's Disease. Mov Disord 2013;28:1737-40. https://doi.org/10.1002/mds.25507

38. Annanmaki T, Pohja M, Parviainen T, Hakkinen P, Murros K. Uric acid and cognition in Parkinson's disease: A follow-up study. Parkinsonism Relat Disord 2011;17:333-7.

https://doi.org/10.1016/j.parkreldis.2011.01.013.

39.Annanmaki T, Pessala-Driver A, Hokkanen L, Murros K. Uric acid associates with cognition in Parkinson's disease. Parkinsonism Relat Disord 2008; 14:576-8.

https://doi.org/10.1016/j.parkreldis.2007.11.001

40.Pellecchia MT, Savastano R, Moccia M, Picillo M, Siano P, Erro R, et al. Lower serum uric acid is associated with mild cognitive impairment in early Parkinson's disease: a 4-year follow-up study. J Neural Transm (Vienna) 2016;123:1399-402.

https://doi.org/10.1007/s00702-016-1622-6

41.Picillo M, Santangelo G, Moccia M, Erro R, Amboni M, Prestipino E, et al. Serum uric acid is associated with apathy in early, drug-naïve Parkinson's disease. J Neural Transm (Vienna) 2016;123:371-7. https://doi.org/10.1007/s00702-015-1502-5

42. Moccia M, Picillo M, Erro R, Vitale $C$, Longo $K$, Amboni $M$, et al. Is serum uric acid related to non-motor symptoms in de-novo Parkinson's disease patients? Parkinsonism Relat Disord 2014;20:772-5. https://doi.org/10.1016/j.parkreldis.2014.03.016

43. Lolekha P, Wongwan P, Kulkantrakorn K. Association between serum uric acid and motor subtypes of Parkinson's disease. J Clin Neurosci $2015 ; 22: 1264-7$.

https://doi.org/10.1016/j.jocn.2015.02.015.

44.Uribe-San Martín $R$, Venegas Francke $P$, López Illanes $F$, Jones Gazmuri A, Salazar Rivera J, Godoy Ferńndez J, et al. Plasma urate in 
REM sleep behavior disorder. Mov Disord 2013;28:1150-1. https://doi.org/10.1002/mds.25441.

45.Rentzos M, Nikolaou C, Anagnostouli M, Rombos A, Tsakanikas K, Economou $M$, et al. Serum uric acid and multiple sclerosis. Clin Neurol Neurosurg 2006;108:527-31.

https://doi.org/10.1016/j.clineuro.2005.08.004

46. Oropesa-Ruiz JM, Huertas-Fernández I, Jesús S, Cáceres-Redondo MT, Vargas-Gonzalez L, Carrillo $F$, et al. Low serum uric acid levels in progressive supranuclear palsy. Mov Disord 2016;31:402-5. https://doi.org/10.1002/mds.26466

47.Eskandarieh S, Heydarpour P, Minagar A, Pourmand S, Sahraian MA. Multiple Sclerosis Epidemiology in East Asia, South East Asia and South Asia: A Systematic Review. Neuroepidemiology 2016;46:20921. https://doi.org/10.1159/000444019

48. Hurwitz B. The diagnosis of multiple sclerosis and the clinical subtypes. Ann Indian Acad Neurol 2009;12:226-30. https://doi.org/10.4103/0972-2327.58276

49.Altınkaynak K, Varoğlu AO, Aksoy H, Deniz O, Aksoy A. Serum Uric Acid Levels in Patients with Relapsing-Remitting Multiple Sclerosis. Eur J Gen Med 2009;6:166-9.

50.Moccia M, Lanzillo R, Palladino R, Russo C, Carotenuto A, Massarelli $M$, et al. Uric acid: A potential biomarker of multiple sclerosis and of its disability. Clin Chem Lab Med 2015;53:753-9. https://doi.org/10.1515/cclm-2014-0744

51.Guerrero AL, Martín-Polo J, Laherrán E, Gutiérrez F, Iglesias F, Tejero MA, et al. Variation of serum uric acid levels in multiple sclerosis during relapses and immunomodulatory treatment. Eur J Neurol 2008;15:394-7. https://doi.org/10.1111/j.14681331.2008.02087.x

52.Toncev G, Vesic K, Aleksic D, Lazarevic S. Higher Serum Uric Acid Levels in Multiple Sclerosis Patients after Long-term Interferon Beta Treatment. Serbian J Exp Clin Res 2017;18:227-30. 10.1007/s10072-011-0488-5.10.1515/sjecr-2016-0052

53.Guerrero AL, Gutiérrez F, Iglesias F, Martín-Polo J, Merino S, Martín-Serradilla JI, et al. Serum uric acid levels in multiple sclerosis patients inversely correlate with disability. Neurol Sci 2011;32:34750. https://doi.org/10.1007/s10072-011-0488-5.

54.Knapp CM, Constantinescu CS, Tan JH, McLean R, Cherryman GR, Gottlob I. Serum uric acid levels in optic neuritis. Mult Scler 2004;10:278-80. https://doi.org/10.1191/1352458504ms1042oa

55. Min JH, Waters $P$, Vincent $A$, Lee $S, Y$ Shin $H, H$ Lee $K$, et al. Reduced serum uric acid levels in neuromyelitis optica: Serum uric acid levels are reduced during relapses in NMO. Acta Neurol Scand 2012;126:287-91.

https://doi.org/10.1111/j.16000404.2012.01643.x

56.Euser SM, Hofman A, Westendorp RGJ, Breteler MMB. Serum uric acid and cognitive function and dementia. Brain 2009;132:377-82. https://doi.org/10.1093/brain/awn316

57.Ye BS, Lee WW, Ham JH, Lee JJ, Lee PH, Sohn YH. Does serum 
uric acid act as a modulator of cerebrospinal fluid Alzheimer's disease biomarker related cognitive decline? Eur J Neurol 2016;23:948-57. https://doi.org/10.1111/ene.12969

58. Hu Q, Liu A, Huang M, Cheng L, Kang $H$, Xu F, et al. Lower serum uric acid levels in cerebral amyloid angiopathy: a pilot study. Neurol Sci 2014;35:1035-9. https://doi.org/10.1007/s10072-014-1634-7

59.Chen X, Guo X, Huang R, Chen Y, Zheng Z, Shang H. Serum uric acid levels in patients with Alzheimer's disease: A meta-analysis. PLoS One 2014;9:e94084.

https://doi.org/10.1371/journal.pone.0094084.

60.Viazzi F, Leoncini G, Ratto E, Pontremoli R. Hyperuricemia and renal risk. High Blood Press Cardiovasc Prev 2014;21:189-94. https://doi.org/10.1007/s40292-014-0042-7

61.Arévalo-Lorido JC, Carretero-Gómez J, Robles Pérez-Monteoliva NR. Association between serum uric acid and carotid disease in patients with atherosclerotic acute ischemic stroke. Vascular 2019;27:19-26. https://doi.org/10.1177/1708538118797551

62.Abeles AM. Hyperuricemia, Gout, and Cardiovascular Disease: An Update. Curr Rheumatol Rep 2015;17:13.

https://doi.org/10.1007/s11926-015-0495-2

63.Schiess M, Oh I. Serum Uric Acid and Clinical Progression in Parkinson Disease: potential biomarker for nigrostriatal failure. Arch Neurol 2008;65:698-9. https://doi.org/10.1001/archneur.65.6.698 64.Liu WC, Hung CC, Chen SC, Yeh SM, Lin MY, Chiu YW, et al. Association of Hyperuricemia with renal outcomes, cardiovascular disease, and mortality. Clin J Am Soc Nephrol 2012;7:541-8. https://doi.org/10.2215/CJN.09420911

65.Amaro S, Soy D, Obach V, Cervera A, Planas AM, Chamorro A. A Pilot Study of Dual Treatment With Recombinant Tissue Plasminogen Activator and Uric Acid in Acute Ischemic Stroke. Stroke 2007;38:2173-5. https://doi.org/10.1161/STROKEAHA.106.480699

66. Amaro S, Urra X, Gomez-Choco M, Obach V, Cervera A, Vargas M, et al. Uric Acid Levels Are Relevant in Patients With Stroke Treated With Thrombolysis. Stroke 2011;42:S28-32.

https://doi.org/10.1161/STROKEAHA.110.596528

67.Paganoni S, Zhang M, Zárate AQ, Jaffa M, Yu H, Cudkowicz ME, et al. Uric acid levels predict survival in men with amyotrophic lateral sclerosis. J Neurol 2012;259:1923-8.

https://doi.org/10.1007/s00415-012-6440-7

68. Auinger P, Kieburtz K, Mcdermott MP. The relationship between uric acid levels and Huntington's disease progression. Mov Disord 2010;25:224-8. https://doi.org/10.1002/mds.22907

69.Kocer A, Münevver O, Buse H, Dilek A, Asuman V. Serum Uric Acid Level as a Prognostic Factor in Benign Essential Tremor. BJMMR 2015;7:604-10. https://doi.org/10.9734/BJMMR/2015/15960

70.Lee CY, Yoon JH, Park JH, Hong JY, Sunwoo MK, Kang SY. Uric acid level may not be reduced in essential tremor. Int J Neurosci 2018;128:1163-7. https://doi.org/10.1080/00207454.2018.1492574 